\title{
Paramedic versus physician-staffed ambulances and prehospital delays in the management of patients with ST-segment elevation myocardial infarction
}

\author{
Artur Borowicz ${ }^{1}$, Klaudiusz Nadolny ${ }^{1,2,3}$, Kamil Bujak ${ }^{4}$, \\ Daniel Cieśla ${ }^{5}$, Mariusz Gąsior ${ }^{4}$, Bartosz Hudzik ${ }^{4,6}$ \\ ${ }^{1}$ Voivodeship Rescue Service in Katowice, Poland \\ ${ }^{2}$ Department of Emergency Medicine, Medical University of Bialystok, Poland \\ ${ }^{3}$ University of Strategic Planning in Dabrowa Gornicza, Poland \\ ${ }^{4} 3^{\text {rd }}$ Department of Cardiology, Silesian Center for Heart Disease, Faculty of Medical Sciences in Zabrze, \\ Medical University of Silesia in Katowice, Poland \\ ${ }^{5}$ Department of Science, Biostatistics and New Technologies, \\ Silesian Center for Heart Disease, Zabrze, Poland \\ ${ }^{6}$ Department of Cardiovascular Disease Prevention, Faculty of Health Sciences in Bytom, \\ Medical University of Silesia in Katowice, Poland
}

\begin{abstract}
Background: Time delays to reperfusion therapy in ST-segment elevation myocardial infarction (STEMI) still remain a considerable drawback in many healthcare systems. Emergency medical service (EMS) has a critical role in the early management of STEMI. Under investigation herein, was whether the use of physician-staffed ambulances leads to shorter pre-hospital delays in STEMI patients.

Methods: This was an observational and retrospective study, using data from the registry of the Silesian regional EMS system in Katowice, Poland and the Polish Registry on Acute Coronary Syndromes (PL-ACS) for a study period of January 1, 2013 to December 31, 2016. The study population $(n=717)$ was divided into two groups: group 1 ( $n=546$ patients) - physician-staffed ambulances and group 2 ( $n=171$ patients) - paramedic-staffed ambulances.

Results: Responses during the day and night shifts were similar. Paramedic-led ambulances more often transmitted 12-lead electrocardiogram (ECG) to the percutaneous coronary intervention centers. All EMS time intervals were similar in both groups. The type of EMS dispatched to patients (physicianstaffed vs. paramedic/nurse-only staffed ambulance) was adjusted for ECG transmission, sex had no impact on in-hospital mortality (odds ratio [OR] 1.41; 95\% confidence interval [CI] 0.79-1.95; $p=0.4)$. However, service time exceeding 42 min was an independent predictor of in-hospital mortality (OR 4.19; 95\% CI 1.27-13.89; $p=0.019$ ). In-hospital mortality rate was higher in the two upper quartiles of service time in the entire study population.

Conclusions: These findings suggest that both physician-led and paramedic-led ambulances meet the criteria set out by the Polish and European authorities. All EMS time intervals are similar regardless of the type of EMS unit dispatched. A physician being present on board did not have a prognostic impact on outcomes. (Cardiol J 2021; 28, 1: 110-117)
\end{abstract}

Key words: acute myocardial infarction, paramedic-only staffed ambulances, physician-staffed ambulances, time delays

Address for correspondence: Assoc. Prof. Bartosz Hudzik, MD, PhD, FESC, FACC, $3^{\text {rd }}$ Department of Cardiology, Silesian Center for Heart Disease, ul. Curie-Skłodowskiej 9, 41-800 Zabrze, Poland, tel: +48 3237336 19, fax: +48 322732679 , e-mail: bartekh@mp.pl

Received: 30.12.2018 Accepted: 23.06.2019

This article is available in open access under Creative Common Attribution-Non-Commercial-No Derivatives 4.0 International (CC BY-NC-ND 4.0) license, allowing to download articles and share them with others as long as they credit the authors and the publisher, but without permission to change them in any way or use them commercially. 


\section{Introduction}

Acute myocardial infarction (AMI) is the leading cause of morbidity and mortality worldwide. In Europe, the incidence varies from 43 to 144 per 100,000 per year [1]. Timely institution of reperfusion therapy is linked to substantial survival benefits. A study by De Luca et al. [2] showed that every $30 \mathrm{~min}$ prolongation in treatment delay was associated with a $7.5 \%$ greater relative risk of 1-year mortality. Despite the introduction of novel interventional techniques and progress in antithrombotic treatment, mortality remains substantial in ST-elevation myocardial infarction (STEMI) patients and varies between $4 \%$ and $12 \%$ in European countries [3].

STEMI management starts from the point of first medical contact when the working diagnosis of STEMI is made (so called "STEMI diagnosis"). Although there have been dramatic changes in the management of STEMI patients over the past several decades, time delays to reperfusion therapy remain a considerable drawback in many healthcare services. Meanwhile, treatment delays are the most easily audited index of quality of care in STEMI [4].

The significance of emergency medical service (EMS) system in the early phases of STEMI is critical, as it is not only a means of transportation, but also enables prompt initiation of proper treatment [4]. European Society of Cardiology (ESC) experts suggests that all ambulances should be equipped with electrocardiogram (ECG) recorders, defibrillators, and at least one person that is certified in advanced life support techniques [4]. The experts believe that the quality of the care is strongly dependent on the training of EMS personnel. The majority of ambulance services worldwide have highly specialized and trained EMS paramedics or nurses on board. However, physician-based EMS systems are present in most European countries [5].

Not every emergent situation requires the presence of a physician on scene. In fact, most EMS interventions do not require the skills of a physician, nor could they be performed at a distance via teleconsultation (phone-assisted medical advice) [6]. Notwithstanding, the use of many advanced life support measures and medications on scene in the pre-hospital setting may require the assistance of a physician or at least a highly specialized EMS paramedic [5]. However, in some situations, e.g. STEMI or respiratory distress, health care systems that provide physician-led ambulances may reduce time delays in diagnosis and treatment of acutely ill patients, and this, in turn, may improve outcomes. Studies show that the presence of a physician in pre-hospital settings improves survival in patients with acute cardio-respiratory emergencies $[7,8]$. Accordingly, Acute Cardiovascular Care Association (ACCA) of the ESC recommends that physician-based EMS organization, have the availability of emergency physicians in cases of chest pain or acute dyspnea of suspected cardiac origin [5].

The evidence for the beneficial effect of a physician's presence on board an ambulance in pre-hospital settings in STEMI patients is lacking. Therefore, this study set out to determine whether the use of physician-staffed ambulances leads to shorter pre-hospital delays which in turn could result in survival benefits for STEMI patients.

\section{Methods}

This study conforms to the Declaration of Helsinki. Informed consent for data analysis was obtained from patients according to Polish law on patient rights regarding data registration. Approval for analyzing recorded data was waived by the institutional review board on human research at the Medical University of Silesia, given the retrospective nature of the study (SUM KNW/0022/ $\mathrm{KB} / 12 / 18)$.

The present study was observational and retrospective in nature, using data from the registry of the Silesian regional EMS system (Voivodeship Rescue Service [VRS]) in Katowice, Poland and the Polish Registry on Acute Coronary Syndromes (PL-ACS) for the study period of January 1, 2013 to December 31, 2016. VRS in Katowice operates in the majority of Silesian regions and covers an area of $3883 \mathrm{~km}^{2}$ (1.2\% of the area of Poland) with approximately $2,700,000$ inhabitants (7\% of the population of Poland) which represents a population density of 695 inhabitants per $1 \mathrm{~km}^{2}$. VRS in Katowice is the biggest public EMS provider in Poland. It operates 88 EMS ambulances including 59 ambulances consisting of 2 paramedics or nurses, and 29 ambulances consisting of 2 paramedics or nurses and 1 physician. Annual call volume is approximately 625,000 with the number of EMS responses of VRS in Katowice being 250,000 per year on average. VRS in Katowice employs highly sophisticated Computer Aided Dispatch hardware and software programs. This fully digitalized system allows for accurate (free of human error) registering of various time intervals essential for the analyses of response times. EMS teams were 
dispatched based on caller complaints and chest pain complaints received priority for the dispatch of physician-staffed EMS. In the event of a lack of available physician-staffed ambulances the first available EMS team (paramedic-staffed) was dispatched to avoid system delays.

The PL-ACS registry is an ongoing, nationwide, multicenter, prospective, observational study of patients hospitalized with ACS. The registry is a joint initiative of the Silesian Center for Heart Disease and the Polish Ministry of Health. A detailed protocol with inclusion and exclusion criteria, methods and definitions has been previously published [9]. The definition of STEMI was based on a widely accepted universal definition of AMI [10].

Based on these two data sources, 870 patients with STEMI were identified. Because inter-hospital transfers form non-percutaneous coronary intervention (PCI) centers to PCI centers has an important impact on outcomes [11] 153 patients were excluded who were transported to non-PCI centers by EMS in order to obtain a homogenous population of patients that would allow analysis of the type of EMS dispatched on the outcomes in patients with STEMI. The study population ( $\mathrm{n}=717$ ) was divided into two groups based on the type of ambulance that was dispatched: group 1 $(\mathrm{n}=546$ patients $)$ - physician-staffed ambulance and group $2(\mathrm{n}=171$ patients $)$ - paramedic/nurse only-staffed ambulance.

In order to accurately analyze EMS response time, the following time intervals were recorded:

- Time to emergency call being answered - the time of the incoming emergency call to be answered by the emergency medical dispatcher (EMD);

- Dispatcher call-processing time - the time interval of the duration of the emergency call and needed for the information captured by an EMD to be entered into the Computer Aided Dispatch;

- Delay time - the time interval between the emergency call received and the ambulance dispatched;

- Response time - the time interval between the ambulance dispatched and ambulance arrival at the scene;

- Field time - the time interval between the emergency call received and the ambulance arrival at the scene (the sum of delay time and response time);

- Service time - the time interval between the ambulance arrival at the scene and ambulance arrival at the hospital;
- Total run time - call time, delay time, response time, response time, and service time amount to the total run time.

\section{Statistical analysis}

Quantitative variables are presented as means and standard deviations or medians and interquartile ranges (lower and upper quartiles) where appropriate. Qualitative variables are presented as frequencies. The Shapiro-Wilk test was used to determine whether random samples came from a normal distribution. The $\chi^{2}$ test with the Yates correction was used to compare categorical variables. The unpaired t-test was used to compare normally-distributed continuous variables between groups. The Mann-Whitney U-test was used to compare continuous variables with a distribution other than normal. In-hospital survival was estimated with the Kaplan-Meier method and compared with the log-rank test. A receiver operating characteristic (ROC) analysis was planned to identify possible cut-offs to predict in-hospital death. All variables with a "p" value of less than 0.05 in the univariate analysis entered into the multivariate logistic regression model using the Wald statistic backward stepwise selection. Multivariate logistic regression analysis was employed to evaluate odds ratios (OR) and 95\% confidence intervals (95\% CI) to identify independent pre-hospital prognostic factors with respect to in-hospital death. A value of $p<0.05$ was considered significant.

\section{Results}

During the study period call volume reached 2,500,000 with 915,345 dispatched EMS units. 870 patients were diagnosed and recorded as STEMI in the pre-hospital setting. $153(17.6 \%)$ patients were transported to non-PCI centers and were excluded from the study in order to obtain a homogenous population. Of 153 patients, 134 were transported by physician-staffed ambulances and 19 were transported by paramedic/nurse-only ambulances. The final study population consisted of 717 patients. The distribution of each component of EMS time intervals for the entire cohort is depicted in Figure 1. The median delay time was $2 \mathrm{~min} 30 \mathrm{~s}$, the median response time was $5 \mathrm{~min}$ and $30 \mathrm{~s}$, the median service time $41 \mathrm{~min}$ and $18 \mathrm{~s}$, and the total run time was $50 \mathrm{~min}$ and $42 \mathrm{~s}$. Baseline clinical characteristics are presented in Table 1. Physician-led ambulances responded more often to male callers. Responses during the day and night shifts were similar. Paramedic-led 


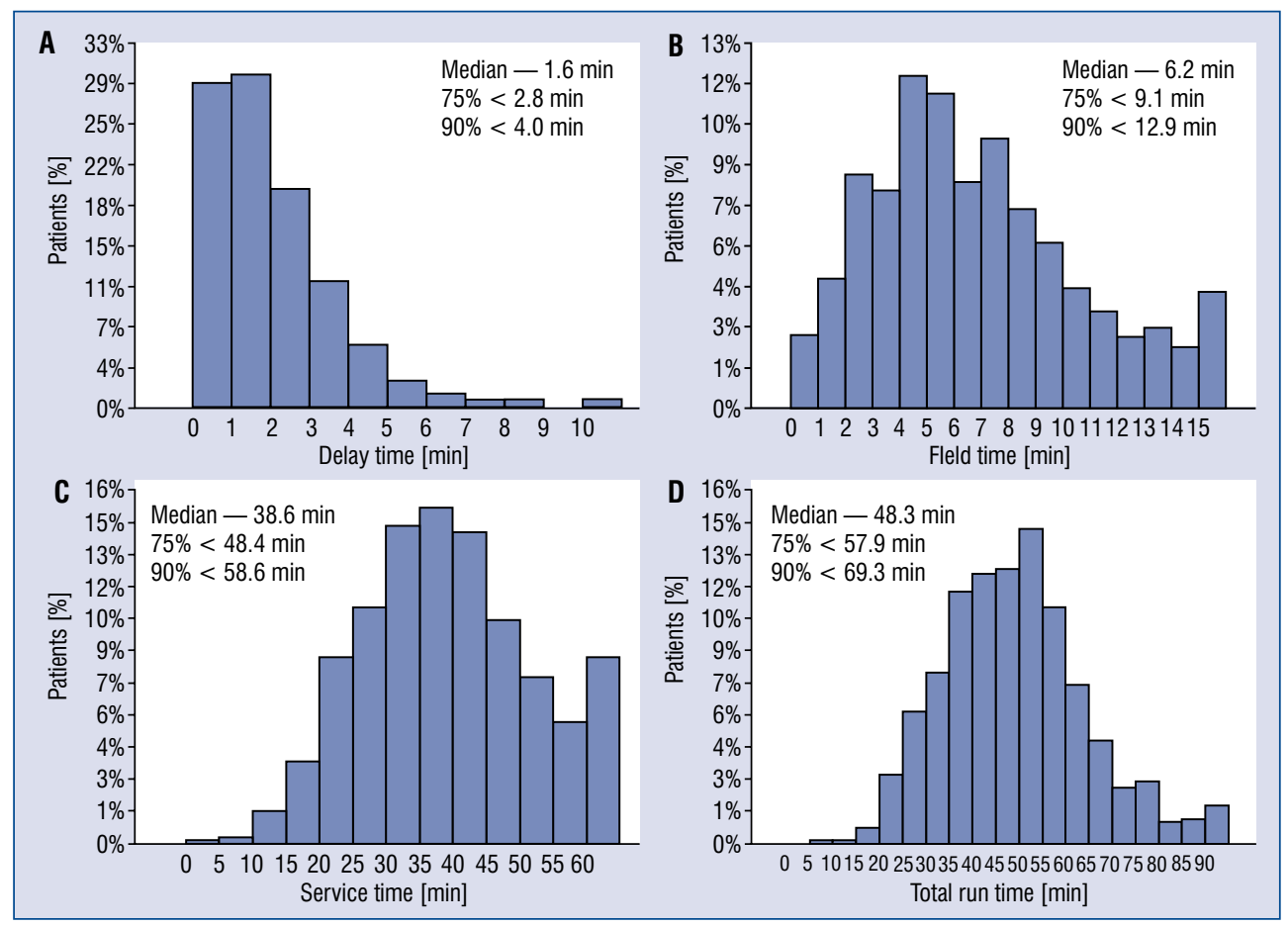

Figure 1. The distribution of each component of the emergency medical service time intervals for the entire cohort; A. Delay time; B. Field time; C. Service time; D. Total run time.

ambulances more often transmitted 12-lead ECG to the PCI center in comparison to physician-led ambulances. Delay times and response times were similar in both study groups. Service time was numerically shorter for physician-led ambulances ( 40.0 min vs. $43.3 \mathrm{~min} ; \mathrm{p}=0.1$ ) however it did not reach statistical significance. In-hospital and long-term mortality was similar in both groups (Table 1, Fig. 2). In the entire cohort, service time of more than $42 \mathrm{~min}$ had a weak value in predicting in-hospital death in ROC analysis (area under curve [AUC] 61; 95\% CI 0.53-0.68; $\mathrm{p}=0.009$ ). The type of EMS dispatched to the patient (physician-staffed vs. paramedic/nurse-only staffed ambulance) adjusted for ECG transmission and sex had no impact on in-hospital mortality (OR $1.41 ; 95 \%$ CI $0.79-1.95 ; \mathrm{p}=0.4$ ). However, service time exceeding 42 min was an independent predictor of in-hospital mortality (OR 4.19; 95\% CI 1.27-13.89; $\mathrm{p}=0.019$ ). The in-hospital mortality rate was higher in the two upper quartiles of service time in the entire study population (Fig. 3).

\section{Discussion}

This study set out to determine whether the presence of the physician in EMS teams responding in STEMI patients has an effect on prehospital delay. Moreover, the aim was to analyze whether the presence of physician-staffed ambulances in an EMS system translates into survival benefits in STEMI patients. There are four key findings of the present study. First and foremost, dispatcher call-processing time, delay time, and the response time are similar irrespective of the presence of a physician on board suggesting that this fact has no bearing on the activation of the EMS system. Moreover, service time was similar in both types of ambulances. More importantly, service time (irrespective of the presence of physician on board) did influence in-hospital mortality and finally, the type of ambulance dispatched to STEMI patients did not have an effect on early or late survival.

Prolonged total ischemic time has been associated with poor outcomes following AMI [2]. It is comprised of both patient delay and system delay. EMS plays a key role in system delays as it may minimize or prolong the time to STEMI diagnosis [4]. Of note, ambulances and EMS are not only the means of transportation to the hospital, but more importantly they enhance prompt diagnosis and management of STEMI patients. Moreover, most patients with signs and symptoms of AMI still demonstrate a considerable delay in seeking treatment, which adds to the overall ischemic time [11]. 
Table 1. Baseline clinical characteristics.

\begin{tabular}{|c|c|c|c|}
\hline & Group 1 ( $n=546)$ & Group 2 ( $n=171)$ & $\mathbf{P}$ \\
\hline Sex, men & $388(71.1 \%)$ & $97(56.7 \%)$ & 0.001 \\
\hline Age [years] & $64 \pm 11$ & $64 \pm 11$ & 0.8 \\
\hline STEMI location: & & & 0.5 \\
\hline Anterior & $197(36.1 \%)$ & $68(39.8 \%)$ & \\
\hline Inferior & $314(57.5 \%)$ & $90(52.6 \%)$ & \\
\hline Other & $35(6.4 \%)$ & $13(7.6 \%)$ & \\
\hline \multicolumn{4}{|l|}{ NYHA class: } \\
\hline I & $348(65.8 \%)$ & $101(59.4 \%)$ & 0.16 \\
\hline II & $153(28.9 \%)$ & $56(32.9 \%)$ & 0.4 \\
\hline III & $5(0.9 \%)$ & $4(2.4 \%)$ & 0.3 \\
\hline IV & $23(4.3 \%)$ & $9(5.3 \%)$ & 0.7 \\
\hline \multicolumn{4}{|l|}{ Kilip class: } \\
\hline 1 & $471(86.3 \%)$ & $142(83.0 \%)$ & 0.3 \\
\hline 2 & $67(12.3 \%)$ & $27(15.8 \%)$ & 0.3 \\
\hline$\geq 3$ & $8(1.5 \%)$ & $2(1.2 \%)$ & 0.9 \\
\hline Hypertension & $370(67.8 \%)$ & $129(75.4 \%)$ & 0.07 \\
\hline Hypercholesterolemia & $261(47.8 \%)$ & $97(56.7 \%)$ & 0.051 \\
\hline Obesity & $93(17.0 \%)$ & $30(17.5 \%)$ & 0.9 \\
\hline Type 2 diabetes mellitus & $123(22.5 \%)$ & $38(22.2 \%)$ & 0.9 \\
\hline Smoking (current or history of) & $327(59.9 \%)$ & $104(60.8 \%)$ & 0.8 \\
\hline Dispatch time of day, 7 AM - 7 PM & $337(61.7 \%)$ & $114(66.6 \%)$ & 0.17 \\
\hline Dispatch code, C1 & $369(67.6 \%)$ & $107(62.6 \%)$ & 0.19 \\
\hline Cardiac arrest & $7(1.3 \%)$ & $0(0 \%)$ & 0.2 \\
\hline ECG transmission & $213(39.0 \%)$ & $102(59.6 \%)$ & $<0.0001$ \\
\hline Body mass index & $27.5 \pm 4.7$ & $28.3 \pm 4.9$ & 0.2 \\
\hline Systolic BP [mmHg] & $134 \pm 25$ & $135 \pm 28$ & 0.7 \\
\hline Diastolic BP [mmHg] & $81 \pm 14$ & $80 \pm 14$ & 0.7 \\
\hline In-hospital death & $29(5.3 \%)$ & $12(7.0 \%)$ & 0.5 \\
\hline
\end{tabular}

BP — blood presuure; ECG — electrocardiogram; STEMI — ST-segment elevation myocardial infarction

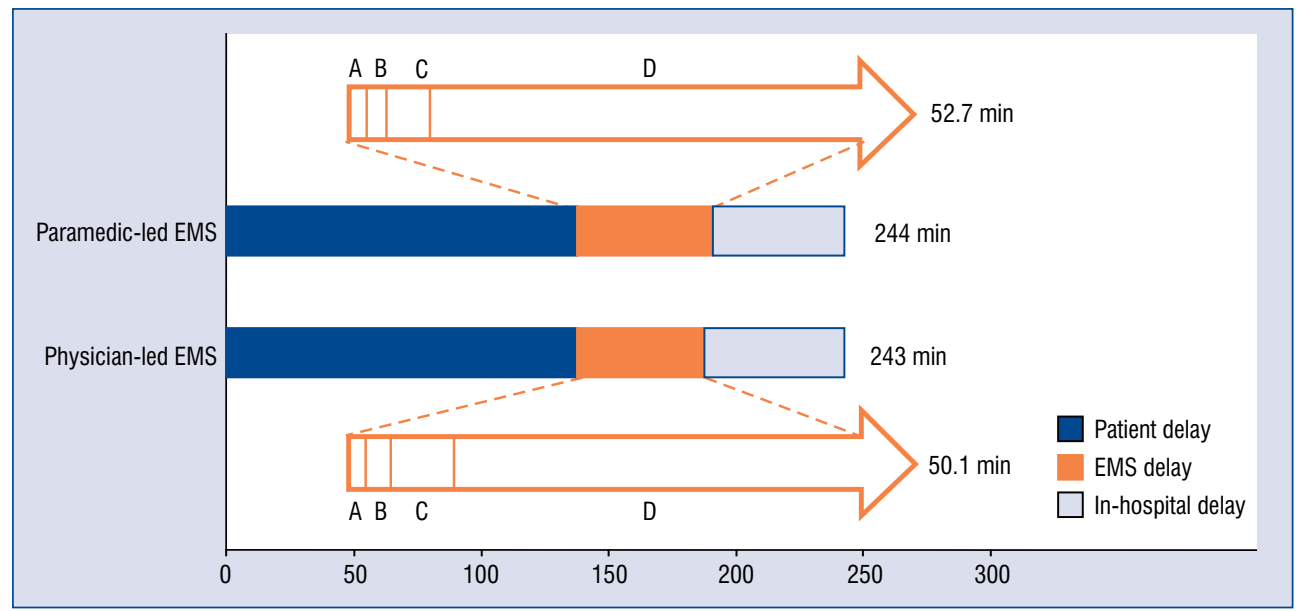

Figure 2. Median total ischemic time in the studied population. Time intervals of the emergency medical service (EMS) delay; $\mathrm{A}$ - dispatcher call-processing time; $\mathrm{B}$ - delay time; $\mathrm{C}$ - response time; $\mathrm{d}$ - service time. 


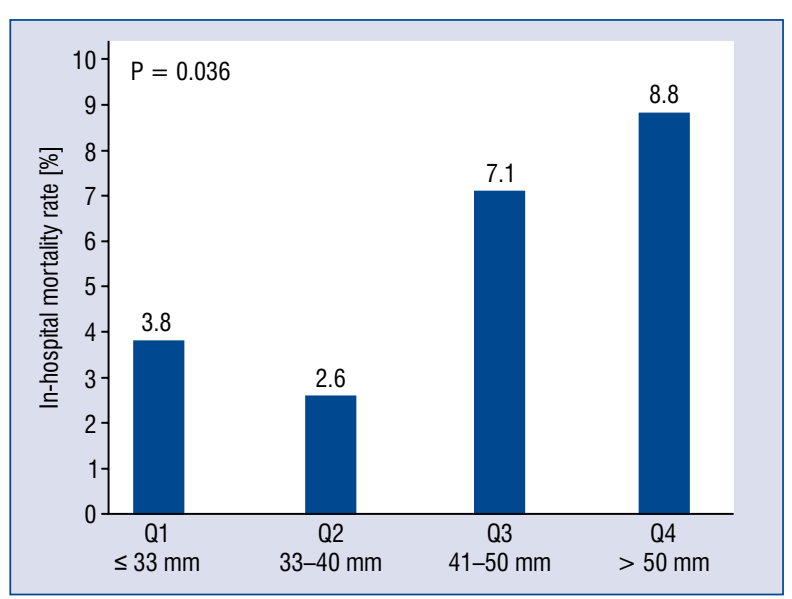

Figure 3. In-hospital mortality rates for quartiles of service time in the entire study population.

Given the STEMI setting may require the presence of emergency physician on-scene in the pre-hospital setting, the ACCA defined delays for diagnosis and treatment in the pre-hospital setting in STEMI patients. And these time intervals are universal for both physician-based and paramedicbased EMS heath care systems [5]. The time between an EMS call and team on scene (the so-called 'Field time') should be no longer than $20 \mathrm{~min}$, but this time limit may differ based on geographic and logistic variations [5]. Results herein, indicate that field time for both physician-led and paramedic-led ambulances are well within recommended time intervals. Notwithstanding, Polish law sets other criteria for ideal time of pre-hospital EMS management of STEMI patients. These times include (a) a median of less than 8 min for field time delays in cities with more than 10,000 inhabitants; (b) a $75^{\text {th }}$ percentile (Q3) of less than 12 min for field time delays in cities with more than 10,000 inhabitants; and c) a maximal field time delay limit is $15 \mathrm{~min}$ in cities with more than 10,000 inhabitants. Although both physician-led and paramedic-led ambulances meet the criteria set out for median and Q3 delays, however maximal field time delays exceeded the proposed timelines in both groups (Table 2).

Several strategies have been proposed for field activation of STEMI networks. These include, among others, transmission of ECG to PCI centers or having physicians involved as part of the ambulance team. These strategies have been linked to better short-term and long-term prognosis [12]. Recording of pre-hospital ECG and notification of PCI center result in a substantial reduction in reperfusion time which in turn leads to survival benefit [13-15]. O'Donnell et al. [16] reported that the availability of prior ECG recordings improved paramedic accuracy in recognizing ST-elevation pattern and diagnosing STEMI. In the present study it was found that only $38.4 \%$ of physician-led ambulances and $60 \%$ of paramedic-led ambulances transmitted ECG recording to a PCI center ( $\mathrm{p}<$ $<0.0001$ ). Studies show similar rates of pre-hospital ECG triage with telemedicine varying between $30 \%$ and $50 \%$ of cases [17-19]. A meta-analysis of non-randomized studies on pre-hospital ECG transmission demonstrated reduction of absolute time to reperfusion by 19 to $114 \mathrm{~min}$ which represented a $19 \%$ to $56 \%$ relative time reductions (95\% CI from $-33 \%$ to $-48 \%$; $p<0.001)$ [17]. Kleinrok et al. [20] showed that during an 8-year period more than 7000 ECG transmissions resulted in admission of nearly 1500 STEMI patients. Zimoch et al. [19] pointed out that pre-hospital ECG transmission results in a higher rate of patients transferred directly to a PCI center $(88 \%$ vs. $63 \%$; $\mathrm{p}=0.002)$. Similarly, it was noticed that the rate

Table 2. Time intervals of emergency medical service responses.

\begin{tabular}{|c|c|c|c|c|c|c|c|}
\hline & \multicolumn{3}{|c|}{ Group $1(n=546)$} & \multicolumn{3}{|c|}{ Group $2(n=171)$} & \multirow[t]{2}{*}{$\mathbf{P}$} \\
\hline & Median & $75 \%$ & $90 \%$ & Median & $75 \%$ & $90 \%$ & \\
\hline Symptom onset -to-emergency call [h] & 2.3 & 6.6 & 22.9 & 2.3 & 6.5 & 23.3 & 0.7 \\
\hline Time to emergency call being answered [s] & 6 & 7 & 7 & 6 & 7 & 7 & 1.0 \\
\hline Dispatcher call-processing time [min] & 1.75 & 2.85 & 3.63 & 1.73 & 2.80 & 2.63 & 0.9 \\
\hline Delay time [min] & 2.5 & 3.5 & 4.63 & 2.3 & 3.3 & 4.0 & 0.3 \\
\hline Response time [min] & 5.6 & 8.8 & 12.0 & 5.0 & 8.4 & 12.5 & 0.5 \\
\hline Field time [min] & 7.9 & 12.0 & 15.2 & 7.3 & 11.2 & 16.1 & 0.3 \\
\hline Service time [min] & 40.0 & 50.0 & 59.5 & 43.3 & 52.0 & 62.0 & 0.1 \\
\hline Total run time [min] & 50.1 & 59.9 & 69.3 & 52.7 & 61.7 & 74.3 & 0.18 \\
\hline
\end{tabular}


of direct transfers to PCI centers in the present screening cohort was higher in paramedic-led ambulances (171/190 [90.0\%] vs. 546/680 [80.3\%]; $\mathrm{p}=0.003$ ) which could have resulted from ECG transmission and direct contact with interventional cardiologists. Although, in-hospital mortality rates in the current study were similar in both groups, it was known that service times were predictive of in-hospital mortality in the entire cohort. Studies implicated inter-hospital transfers (from non-PCI centers to PCI centers) resulted in substantial delays in receiving reperfusion therapy, thereby causing subsequent larger myocardial damage [21-24]. Kawecki et al. [21] indicated that direct admission to a PCI center resulted in a shorter median symptoms-to-admission time (by $44 \mathrm{~min}$; $\mathrm{p}<0.001)$ and a lower 12 -month mortality $(9.6 \%$ vs. $10.4 \%$; $\mathrm{p}<0.001)$. However, results are inconsistent and other studies did not confirm these findings [25-27]. Notwithstanding, comparing to previous studies, rates of direct transfers to PCI centers in the present study were much higher for both physician-led and paramedic-led ambulances.

\section{Limitations of the study}

The study should be viewed with regard to its limitations. This is a single-region, retrospective, observational study. The studied region is densely populated with a high number of EMS stations and PCI centers (STEMI networks). Thus, current results may be region-specific and may differ from other geographic regions. Unfortunately, medical treatment in the pre-hospital setting was not recorded and, thus, not reported. It would be interesting to see whether there are any differences in the therapeutic approach to STEMI patients (antithrombotic strategies in particular) for physician-led and paramedic-led ambulances. EMS teams were dispatched based on the caller complaints, but sometimes the first available EMS team was dispatched.

\section{Conclusions}

Taken together, these findings suggest that both physician-led and paramedic-led ambulances meet the time criteria set out by the Polish and European authorities and scientific organizations. All time intervals associated with EMS management of STEMI patients are similar regardless of the type of EMS unit dispatched to the scene. The presence or absence of a physician on board did not have a prognostic impact on outcomes.

Notwithstanding, this study has identified a few areas of management that require further improvement for all ambulances. There is an urgent need for more frequent pre-hospital ECG transmission and triage, in physician-led ambulances in particular. This could increase the number of patients transferred directly to PCI centers. This, in turn, could result in prominent reductions in ischemic time.

\section{Conflict of interest: None declared}

\section{References}

1. Widimsky P, Wijns W, Fajadet J, et al. Reperfusion therapy for ST elevation acute myocardial infarction in Europe: description of the current situation in 30 countries. Eur Heart J. 2010; 31(8): 943-957, doi: 10.1093/eurheartj/ehp492, indexed in Pubmed: 19933242 .

2. De Luca G, Suryapranata H, Ottervanger JP, et al. Time delay to treatment and mortality in primary angioplasty for acute myocardial infarction: every minute of delay counts. Circulation. 2004; 109(10): 1223-1225, doi: 10.1161/01.CIR.0000121424.76486.20, indexed in Pubmed: 15007008.

3. Kristensen SD, Laut KG, Fajadet J, et al. Reperfusion therapy for ST elevation acute myocardial infarction 2010/2011: current status in 37 ESC countries. Eur Heart J. 2014; 35(29): 1957-1970, doi: 10.1093/eurheartj/eht529, indexed in Pubmed: 24419804.

4. Ibanez B, James S, Agewall S, et al. 2017 ESC Guidelines for the management of acute myocardial infarction in patients presenting with ST-segment elevation: The Task Force for the management of acute myocardial infarction in patients presenting with ST-segment elevation of the European Society of Cardiology (ESC). Eur Heart J. 2018; 39(2): 119-177, doi: 10.1093/eurheartj/ ehx393, indexed in Pubmed: 28886621.

5. Beygui F, Castren M, Brunetti ND, et al. Pre-hospital management of patients with chest pain and/or dyspnoea of cardiac origin. A position paper of the Acute Cardiovascular Care Association (ACCA) of the ESC. Eur Heart J Acute Cardiovasc Care. 2015 [Epub ahead of print], doi: 10.1177/2048872615604119, indexed in Pubmed: 26315695.

6. Haner A, Örninge P, Khorram-Manesh A. The role of physicianstaffed ambulances: the outcome of a pilot study. J Acute Dis. 2015; 4(1): 63-67, doi: 10.1016/s2221-6189(14)60086-x.

7. Böttiger BW, Bernhard M, Knapp J, et al. Influence of EMSphysician presence on survival after out-of-hospital cardiopulmonary resuscitation: systematic review and meta-analysis. Crit Care. 2016; 20: 4, doi: 10.1186/s13054-015-1156-6, indexed in Pubmed: 26747085.

8. Hagihara A, Hasegawa M, Abe T, et al. Physician presence in an ambulance car is associated with increased survival in out-ofhospital cardiac arrest: a prospective cohort analysis. PLoS One. 2014; 9(1): e84424, doi: 10.1371/journal.pone.0084424, indexed in Pubmed: 24416232.

9. Polonski L, Gasior G, Gierlotka M, et al. Polish Registry of Acute Coronary Syndromes (PL-ACS). Characteristics, treatments and outcomes of patients with acute coronary syndromes in Polan. Kardiol Pol. 2007; 65(8): 861-872.

10. Steg PhG, James SK, Atar D, et al. ESC Guidelines for the management of acute myocardial infarction in patients presenting with ST-segment elevation. Eur Heart J. 2012; 33(20): 2569-2619, doi: 10.1093/eurheartj/ehs215, indexed in Pubmed: 22922416. 
11. McGinn AP, Rosamond WD, Goff DC, et al. Trends in prehospital delay time and use of emergency medical services for acute myocardial infarction: experience in 4 US communities from 1987-2000. Am Heart J. 2005; 150(3): 392-400, doi: 10.1016/j. ahj.2005.03.064, indexed in Pubmed: 16169313.

12. Goldstein P, Lapostolle F, Steg G, et al. Lowering mortality in ST-elevation myocardial infarction and non-ST-elevation myocardial infarction: key prehospital and emergency room treatment strategies. Eur J Emerg Med. 2009; 16(5): 244-255, doi: 10.1097/ MEJ.0b013e328329794e, indexed in Pubmed: 19318957.

13. Savage ML, Poon KKC, Johnston EM, et al. Pre-hospital ambulance notification and initiation of treatment of ST elevation myocardial infarction is associated with significant reduction in door-to-balloon time for primary PCI. Heart Lung Circ. 2014; 23(5): 435-443, doi: 10.1016/j.hlc.2013.11.015, indexed in Pubmed: 24388497.

14. Curtis JP, Portnay EL, Wang Y, et al. The pre-hospital electrocardiogram and time to reperfusion in patients with acute myocardial infarction, 2000-2002: findings from the National Registry of Myocardial Infarction-4. J Am Coll Cardiol. 2006; 47(8): 1544-1552, doi: 10.1016/j.jacc.2005.10.077, indexed in Pubmed: 16630989.

15. Morrison LJ, Brooks S, Sawadsky B, et al. Prehospital 12-lead electrocardiography impact on acute myocardial infarction treatment times and mortality: a systematic review. Acad Emerg Med. 2006; 13(1): 84-89, doi: 10.1197/j.aem.2005.07.042, indexed in Pubmed: 16365334.

16. O'Donnell D, Mancera M, Savory E, et al. The availability of prior ECGs improves paramedic accuracy in recognizing ST-segment elevation myocardial infarction. J Electrocardiol. 2015; 48(1): 93-98, doi: 10.1016/j.jelectrocard.2014.09.003, indexed in Pubmed: 25282555.

17. Brunetti ND, De Gennaro L, Correale M, et al. Pre-hospital electrocardiogram triage with telemedicine near halves time to treatment in STEMI: A meta-analysis and meta-regression analysis of non-randomized studies. Int J Cardiol. 2017; 232: 5-11, doi: 10.1016/j.ijcard.2017.01.055, indexed in Pubmed: 28089154 .

18. Brunetti ND, Bisceglia L, Dellegrottaglie G, et al. Lower mortality with pre-hospital electrocardiogram triage by telemedicine support in high risk acute myocardial infarction treated with primary angioplasty: Preliminary data from the Bari-BAT public Emergency Medical Service 118 registry. Int J Cardiol. 2015; 185: 224-228, doi: 10.1016/j.ijcard.2015.03.138, indexed in Pubmed: 25797682.

19. Zimoch WJ, Kosowski M, Tomasiewicz B, et al. Impact of prehospital electrocardiogram teletransmission on time delays in ST segment elevation myocardial infarction patients: a single-centre experience. Postepy Kardiol Interwencyjnej. 2015; 11(3): 212-217, doi: 10.5114/pwki.2015.54016, indexed in Pubmed: 26677362.

20. Kleinrok A, Płaczkiewicz DT, Puźniak M, et al. Electrocardiogram teletransmission and teleconsultation: essential elements of the organisation of medical care for patients with ST segment elevation myocardial infarction: a single centre experience. Kardiol Pol. 2014; 72(4): 345-354, doi: 10.5603/KP.a2013.0352, indexed in Pubmed: 24408066.

21. Kawecki D, Gierlotka M, Morawiec B, et al. Direct Admission Versus Interhospital Transfer for Primary Percutaneous Coronary Intervention in ST-Segment Elevation Myocardial Infarction. JACC Cardiovasc Interv. 2017; 10(5): 438-447, doi: 10.1016/j.jcin.2016.11.028, indexed in Pubmed: 28216215.

22. Nakatsuma K, Shiomi H, Morimoto T, et al. Inter-Facility transfer vs. Direct admission of patients with ST-segment elevation acute myocardial infarction undergoing primary percutaneous coronary intervention. Circ J. 2016; 80(8): 1764-1772, doi: 10.1253/circj. CJ-16-0204, indexed in Pubmed: 27350014.

23. Le May MR, Wells GA, So DY, et al. Reduction in mortality as a result of direct transport from the field to a receiving center for primary percutaneous coronary intervention. J Am Coll Cardiol. 2012; 60(14): 1223-1230, doi: 10.1016/j.jacc.2012.07.008, indexed in Pubmed: 23017532.

24. Chan AW, Kornder J, Elliott H, et al. Improved survival associated with pre-hospital triage strategy in a large regional ST-segment elevation myocardial infarction program. JACC Cardiovasc Interv. 2012; 5(12): 1239-1246, doi: 10.1016/j.jcin.2012.07.013, indexed in Pubmed: 23257372.

25. Henry TD, Sharkey SW, Burke MN, et al. A regional system to provide timely access to percutaneous coronary intervention for ST-elevation myocardial infarction. Circulation. 2007; 116(7): 721-728, doi: 10.1161/CIRCULATIONAHA.107.694141, indexed in Pubmed: 17673457.

26. Wöhrle J, Desaga M, Metzger C, et al. Impact of transfer for primary percutaneous coronary intervention on survival and clinical outcomes (from the HORIZONS-AMI Trial). Am J Cardiol. 2010; 106(9): 1218-1224, doi: 10.1016/j.amjcard.2010.06.049, indexed in Pubmed: 21029816.

27. Busk M, Maeng M, Rasmussen K, et al. The Danish multicentre randomized study of fibrinolytic therapy vs. primary angioplasty in acute myocardial infarction (the DANAMI-2 trial): outcome after 3 years follow-up. Eur Heart J. 2008; 29(10): 1259-1266, doi: 10.1093/eurheartj/ehm392, indexed in Pubmed: 17956874. 